\title{
El Niño, La Niña, and the global sea level budget
}

\author{
Christopher G. Piecuch and Katherine J. Quinn \\ Atmospheric and Environmental Research, Inc., Lexington, MA 02421, USA \\ Correspondence to: Christopher G. Piecuch (cpiecuch@aer.com) \\ Received: 15 August 2016 - Published in Ocean Sci. Discuss.: 26 August 2016 \\ Revised: 28 October 2016 - Accepted: 31 October 2016 - Published: 11 November 2016
}

\begin{abstract}
Previous studies show that nonseasonal variations in global-mean sea level (GMSL) are significantly correlated with El Niño-Southern Oscillation (ENSO). However, it has remained unclear to what extent these ENSO-related GMSL fluctuations correspond to steric (i.e., density) or barystatic (mass) effects. Here we diagnose the GMSL budget for ENSO events observationally using data from profiling floats, satellite gravimetry, and radar altimetry during 2005-2015. Steric and barystatic effects make comparable contributions to the GMSL budget during ENSO, in contrast to previous interpretations based largely on hydrological models, which emphasize the barystatic component. The steric contributions reflect changes in global ocean heat content, centered on the Pacific. Distributions of ocean heat storage in the Pacific arise from a mix of diabatic and adiabatic effects. Results have implications for understanding the surface warming slowdown and demonstrate the usefulness of the Global Ocean Observing System for constraining Earth's hydrological cycle and radiation imbalance.
\end{abstract}

\section{Introduction}

Sea level is an informative index of climate and serious concern for coastal communities. Hence, understanding the modern altimetry record is important from scientific and societal vantage points. The most apparent signals in the altimetric global-mean sea level (GMSL) data are the annual cycle and linear trend (e.g., Fig. 4 in Masters et al., 2012). In principle, these changes in the global ocean's water volume relate to the ocean's mass and its density, referred to as "barystatic" and "steric" sea level changes, respectively (e.g., Gregory et al., 2013; Leuliette, 2015). Past studies have successfully used in situ hydrography and satellite gravity data to assess ocean mass and density changes and to evalu- ate barystatic and steric effects on the annual cycle and the linear trend in GMSL (e.g., Lombard et al., 2007; Willis et al., 2008; Cazenave et al., 2009; Leuliette and Miller, 2009; Leuliette and Willis, 2011; Leuliette, 2014, 2015).

Although the annual cycle and linear trend are the most prominent signals in the record, altimeter data also evidence more subtle GMSL variations superimposed on those signals. In particular, it has long been reported that nonseasonal GMSL anomalies are significantly correlated with El NiñoSouthern Oscillation (ENSO), such that the GMSL is anomalously positive during warm El Niño phases and anomalously negative during cool La Niña phases (Nerem et al., 1999, 2010; Chambers et al., 2002; Ngo-Duc et al., 2005; Landerer et al., 2008; Merrifield et al., 2009; Llovel et al., 2010, 2011; Boening et al., 2012; Cazenave et al., 2012, 2014; Meyssignac and Cazenave, 2012; Stammer et al., 2013; Fasullo et al., 2013; Haddad et al., 2013; Meyssignac et al., 2013; Calafat et al., 2014; Dieng et al., 2014, 2015; Pugh and Woodworth, 2014). Recent papers argue that ENSO-related GMSL changes are essentially of barystatic origin, related to changes in the hydrological cycle, and patterns of precipitation and evaporation (Llovel et al., 2011; Boening et al., 2012; Cazenave et al., 2012, 2014; Fasullo et al., 2013). However, these papers are based on either observations during an isolated event or correlation analysis of model output, and the extent to which barystatic or steric effects are responsible for ENSO-related GMSL fluctuations more generally has not been firmly established based on observations. In fact, conflicting accounts of the GMSL budget during ENSO events are given in the literature. For example, based on altimetry, sea-surface temperature data, and ocean model output, Nerem et al. (1999) reason that the anomalous GMSL rise during the 1997-1998 El Niño was due to thermal expansion of the upper ocean. In contrast, using altimetry and global hydrological models, Ngo-Duc et al. (2005), Llovel et 
al. (2011), and Cazenave et al. (2012) argue that this anomalous rise in GMSL was owing to an increase in global ocean mass. On the one hand, based on satellite data and in situ observations, Boening et al. (2012) and Fasullo et al. (2013) conclude that the anomalous fall in GMSL during the 20102011 La Niña was related to a decrease in global ocean mass. On the other hand, and based on very similar datasets, Dieng et al. (2014) conclude differently, finding that this anomalous GMSL fall was owing in approximately equal parts to barystatic and steric contributions.

The literature thus paints a confusing picture. Clarifying the nature of ENSO-related GMSL variations is important for understanding the ocean's role in Earth's hydrological cycle and energy imbalance (e.g., Fasullo et al., 2013; Leuliette, 2015). Here we exploit the growing record length of the Global Ocean Observing System, analyzing satellite gravity, radar altimetry, and in situ hydrographic observations using linear estimation (regression) to elucidate observationally the nature of the altimetric GMSL budget for ENSO events.

\section{Datasets}

\subsection{Satellite altimetry}

We study GMSL records from four groups: AVISO (Ablain et al., 2009), Colorado (Nerem et al., 2010), NOAA (Leuliette and Scharroo, 2010), and CSIRO (Church and White, 2011). Time series derive from the reference altimetry missions (TOPEX/Poseidon, Jason-1, -2). The standard corrections (postglacial rebound, wet troposphere, inverted barometer) are made and a 60-day filter is used to remove a spurious 59-day signal (Masters et al., 2012). Time series are interpolated onto regular monthly intervals over 1993-2015 and we use the ensemble average across the interpolated records. A standard error (Table 1) is estimated based on variances in differences between time series (cf. Ponte and Dorandeu, 2003).

\subsection{Profiling floats}

Monthly Argo in situ temperature and salinity grids produced by Scripps Institution of Oceanography (SIO) and International Pacific Research Center (IPRC) are also employed. The grids are generated using objective analysis applied to quality controlled float profiles (Roemmich and Gilson, 2009). Fields span from $65^{\circ} \mathrm{S}$ to $65^{\circ} \mathrm{N}$ latitudinally, and down to $\sim 2000 \mathrm{~m}$, but do not cover marginal shelf seas. We use the data for the period 2005-2015, since float coverage was not sufficient before then (Leuliette, 2015, and references therein). We use these gridded fields to evaluate steric sea level following Gill and Niiler (1973). And as with altimetry data, we use the average of the SIO and IPRC time series, deriving a standard error using the difference between these products (Ponte and Dorandeu, 2003).

\subsection{Gravimetric retrievals}

Monthly estimates of the barystatic sea level term based on retrievals from the Gravity Recovery and Climate Experiment (GRACE) (e.g., Tapley et al., 2004) are also considered. Values are from Release- 05 data processed by the three main science data system centers at the University of Texas at Austin Center for Space Research (CSR; Bettadpur, 2012), the Jet Propulsion Laboratory (JPL; Watkins and Yuan, 2012), and the GeoForschungsZentrum Potsdam (GFZ; Dahle, 2013). These data are then postprocessed by Don P. Chambers at the University of South Florida following the methods detailed in Chambers and Bonin (2012) and Johnson and Chambers (2013). We consider the ensemble mean across the estimates, deriving an estimate of the standard error according to variances in the differences between series (Ponte and Dorandeu, 2003). To be overlapping with Argo, we consider the GRACE ocean mass data over 20052015.

\section{Results and discussion}

Figure 1a shows nonseasonal anomalies of GMSL (i.e., annual cycle and trend removed) alongside the Multivariate ENSO Index (MEI) (Wolter and Timlin, 1998) over 20052015. As in earlier papers cited above, there is a tight relation between GMSL and MEI curves, such that the GMSL is higher during El Niño periods and lower during La Niña periods. The Pearson product-moment correlation coefficient (hereafter simply referred to as the correlation) between these two records (0.73) is significant at the $95 \%$ confidence level and suggests that approximately half of the nonseasonal anomalous GMSL variance over this period corresponds to ENSO. More generally, we observe that correlation between the nonseasonal GMSL and MEI anomalies is significant for all other 11-year periods during the altimeter record, as well as for the entire 23-year altimetric record itself (not shown).

Nonseasonal GMSL anomalies from satellite altimetry data are consistent with the sum of barystatic and steric components from GRACE and Argo (Fig. 1b). The correlations between GMSL from GRACE and Argo and from altimetry (0.89), and between MEI and the sum of GRACE and Argo (0.67), are both significant. Correlation values between GRACE and the MEI (0.54; Fig. 1c) and Argo and the MEI (0.65; Fig. 1d) are also significant. In fact, all pairs of time series displayed in Fig. 1 are significantly correlated (not shown). These results suggest that GMSL fluctuations tied to ENSO and seen by satellite altimetry are independently corroborated by the other ocean observing platforms and that barystatic and steric terms both contribute to the significant relationship between GMSL and ENSO.

To consider the GMSL budget related to ENSO more formally, we use linear estimation, namely ordinary least squares (OLS). We model the data as linear combinations 
Table 1. Results of OLS applied to altimetric GMSL $(\eta)$, GRACE barystatic sea level $\left(p_{\mathrm{b}}\right)$, Argo steric sea level $\left(\eta_{\rho}\right)$, and linear combinations thereof. Values are given as $90 \%$ confidence intervals as described in Appendix B. Note that, while the predictors of the OLS fit include an annual sine and cosine, we present results here transformed into the amplitude and phase of a sine term using standard trigonometric transformations. Note also that $n^{*}$ is the effective number of data points (evaluated following Eq. A3 in the Appendix), whereas $\delta_{Y}$ is the standard error evaluated for the different data as outlined in Sect. 2.

\begin{tabular}{lrrrrrr}
\hline & $\begin{array}{r}\text { Trend } \\
\left(\mathrm{mm} \mathrm{yr}^{-1}\right)\end{array}$ & $\begin{array}{r}\text { MEI } \\
\left(\mathrm{mm} \mathrm{MEI}^{-1}\right)\end{array}$ & $\begin{array}{r}\text { Amplitude } \\
(\mathrm{mm})\end{array}$ & $\begin{array}{r}\text { Phase } \\
\left({ }^{\circ}\right)\end{array}$ & $n^{*}$ & $\begin{array}{r}\delta_{Y} \\
(\mathrm{~mm})\end{array}$ \\
\hline$\eta$ & $3.39 \pm 0.55$ & $2.76 \pm 1.87$ & $5.74 \pm 2.40$ & $-36 \pm 24$ & 12 & 1.29 \\
$p_{\mathrm{b}}+\eta_{\rho}$ & $3.22 \pm 0.43$ & $2.97 \pm 1.47$ & $5.81 \pm 1.90$ & $-24 \pm 19$ & 22 & 1.88 \\
$p_{\mathrm{b}}$ & $2.23 \pm 0.44$ & $1.54 \pm 1.50$ & $10.04 \pm 1.92$ & $-52 \pm 11$ & 14 & 1.44 \\
$\eta_{\rho}$ & $0.99 \pm 0.16$ & $1.42 \pm 0.53$ & $5.61 \pm 0.68$ & $99 \pm 7$ & 49 & 1.21 \\
$\eta-p_{\mathrm{b}}-\eta_{\rho}$ & $0.18 \pm 0.19$ & $-0.20 \pm 0.64$ & $1.26 \pm 0.82$ & $-123 \pm 37$ & 48 & 2.28 \\
\hline
\end{tabular}
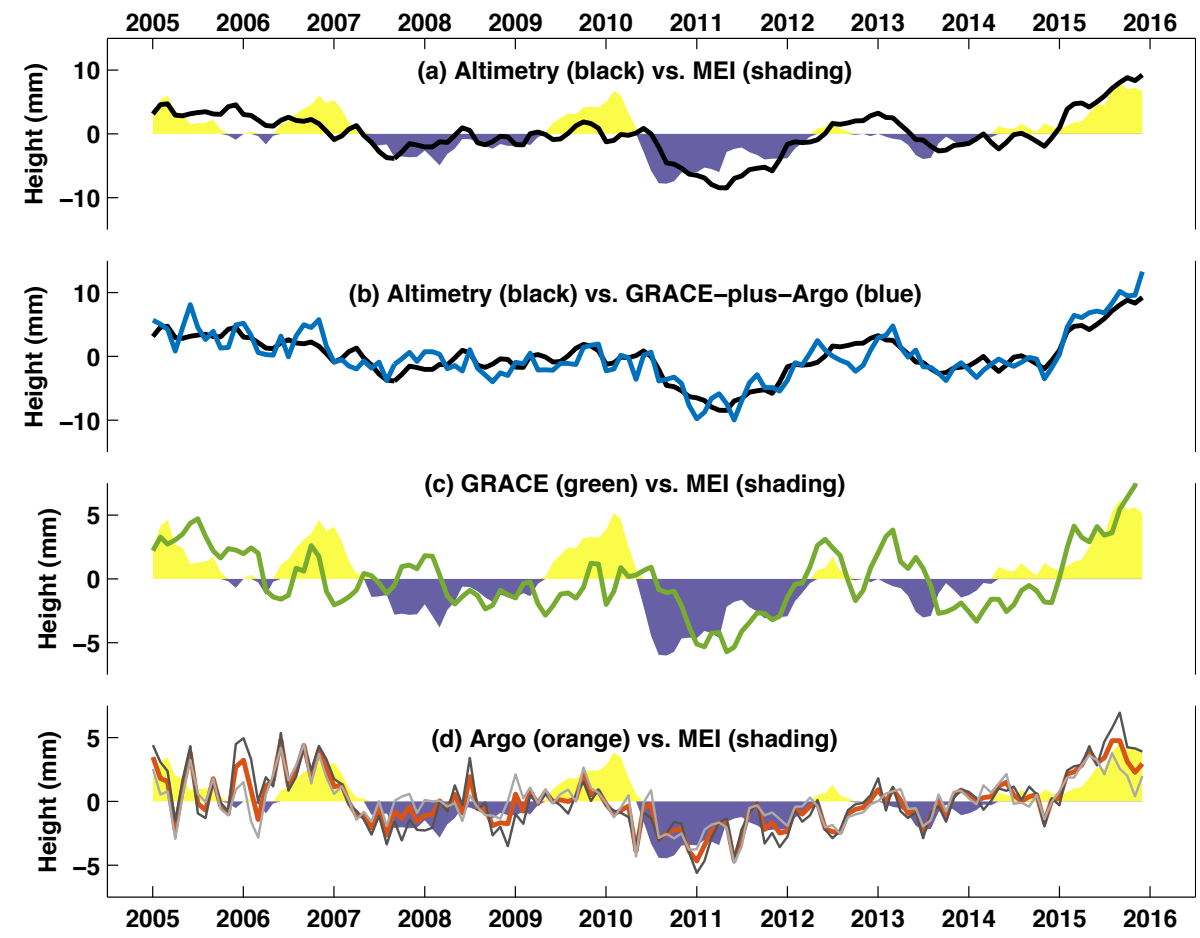

Figure 1. Monthly time series over 2005-2015 of (a) altimetric GMSL (black) and the MEI (shading), (b) GMSL from altimetry (black) and from GRACE and Argo (blue), (c) GRACE barystatic sea level (green) and the MEI (shading), and (d) Argo steric sea level (orange) and the MEI (shading). The thin dark gray (light gray) curve in (d) is Argo steric sea level based on the SIO (IPRC) gridded dataset. Linear trends and annual cycles have been removed from all time series. The MEI record has been scaled to have variance equal to that of the respective sea level time series.

of decadal trend, annual cycle, and MEI regressors, simultaneously solving for the regression coefficients for all predictors by minimizing the residual. This particular form of linear regression is motivated by previous studies referenced in the Introduction. (Indeed, the regression explains $\gtrsim 90 \%$ of the variance in the GMSL, barystatic, and steric curves over 2005-2015, and the coefficients of the regressors are all statistically significant, as revealed in Table 1 and discussed in more detail below, suggesting that this form of regression model is justified.) While OLS assumes the residuals behave as white noise, in practice we find that residuals are serially correlated (not shown). Thus, we inflate the standard errors according to the lag-1 autocorrelation and the effective degrees of freedom as detailed in Chambers et al. (2012) and Calafat and Chambers (2013). More technical details of our methods are found in Appendix A.

Table 1 shows results of this OLS procedure applied to altimetry, GRACE, and Argo. All quoted values are $90 \%$ confidence intervals as described in Appendix B. (Since they are not our focus here, we defer discussion of results for the annual cycle and linear trend to Appendix C.) Per unit MEI change, altimetric GMSL changes by $2.76 \pm 1.87 \mathrm{~mm}$, 
which is close to the value of $2.97 \pm 1.47 \mathrm{~mm}$ given by the sum of Argo steric and GRACE barystatic terms. Indeed, the residual value is not statistically distinguishable from zero $(-0.20 \pm 0.64 \mathrm{~mm})$, showing that the GMSL budget related to ENSO can be closed using observational data. Closure of the budget implies that steric contributions from regions not sampled by Argo (shelf seas, Arctic Ocean, below $2000 \mathrm{~m}$ ) cannot be detected over the study period. Llovel et al. (2014) reach a similar conclusion regarding deep ocean steric contributions to the GMSL trend budget over 2005-2013. Significant regression coefficients are also determined for Argo steric $(1.42 \pm 0.53 \mathrm{~mm})$ and GRACE barystatic $(1.54 \pm 1.50 \mathrm{~mm})$ components. The error bars on the barystatic term are comparatively wider than on the steric term, agreeing with the relatively stronger correlation between Argo and MEI than between GRACE and MEI seen above (Fig. 1).

The OLS regression coefficients demonstrate that steric and barystatic effects generally make comparable contributions to the ENSO-related GMSL changes over the study period. Judging from Monte Carlo simulations performed using values in Table 1 (see Appendix D), it is as likely as not (33-66\% likelihood) that barystatic effects are responsible for $45-58 \%$ of the sum of barystatic and steric contributions to GMSL variations linked to ENSO, and very unlikely ( $<10 \%$ likelihood) that the barystatic term amounts to $>68 \%$ (Fig. 2). This is at odds with the emphasis placed on the barystatic contribution by recent studies (e.g., Llovel et al., 2011; Cazenave et al., 2012, 2014), revealing that, at least over this time period, the steric component is equally as important.

Regional distributions of ENSO-related terrestrial water storage, which are ultimately coupled to the barystatic contributions to GMSL fluctuations through mass conservation, are explored in past papers (Llovel et al., 2011; Boening et al., 2012; Phillips et al., 2012; Fasullo et al., 2013; de Linage et al., 2013; Eicker et al., 2016); they are not revisited here. However, ENSO-related GMSL behavior owing to steric effects is not as well understood. The steric contributions to the GMSL fluctuations related to ENSO arise from changes in ocean heat content. Arguments based on mass conservation (Munk, 2003) suggest that any global steric contributions resulting from salinity changes would be exceedingly small. To elucidate ocean heat content changes potentially contributing to GMSL changes related to ENSO, we apply the OLS method to Argo vertical potential temperature profiles, averaging horizontally over the global ocean as well as individual ocean basins (Fig. 3).

There is significant warming of the global ocean's surface waters $(0-100 \mathrm{~m})$ and cooling within its main thermocline (130-320 m) during El Niño periods. Marginally significant warming also occurs at some intermediate depths (600$650 \mathrm{~m})$. On the whole, the global upper ocean $(0-2000 \mathrm{~m})$ gains $5.5 \pm 5.2 \mathrm{ZJ}\left(\mathrm{ZJ} \equiv 10^{21} \mathrm{~J}\right)$ of heat per unit of MEI increase (equivalent to a uniform global ocean temperature

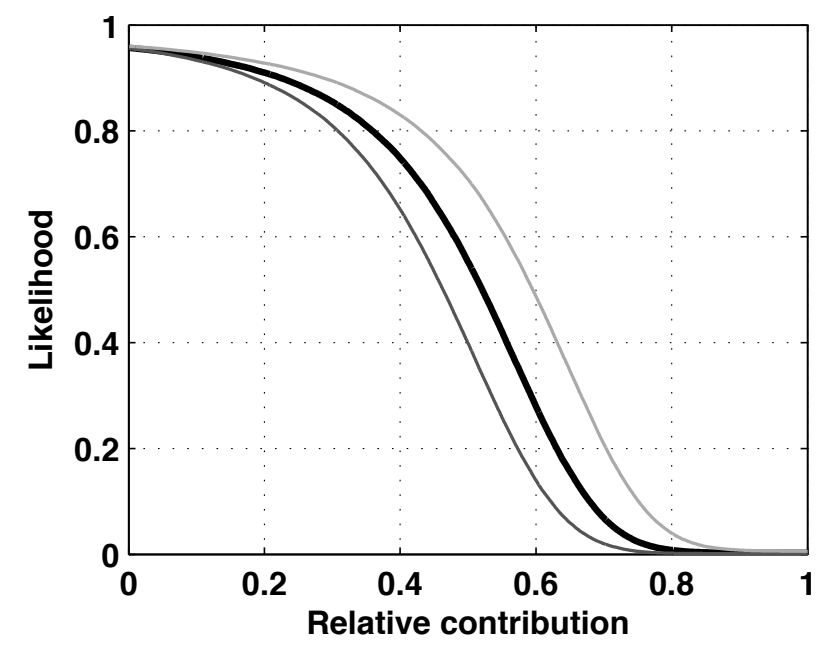

Figure 2. The thick black curve is the likelihood that the barystatic contribution to ENSO-related GMSL changes will exceed a certain fraction of the sum of barystatic and steric terms based on Monte Carlo runs, where the steric term is evaluated based on the average of the SIO and IPRC gridded data products. The thin dark gray (light gray) curve is that same likelihood but with the steric term assessed using only the SIO (IPRC) product.

variation on the order of $0.001{ }^{\circ} \mathrm{C}$ ). While there are some significant thermal changes related to ENSO observed in other basins at some depths $(<60 \mathrm{~m}$ in the Indian; $>1350 \mathrm{~m}$ in the Atlantic; see Fig. 3 caption for basin definitions), the vertical structure of the global ocean's ENSO-related thermal variations derives from the Pacific, where there is similar warming near the surface $(0-110 \mathrm{~m})$, cooling in the thermocline (130-320 m), and warming of intermediate waters (500-1150 m). Indeed, only the Pacific shows significant net thermal changes during ENSO, which is hardly surprising as ENSO originates from coupled air-sea interactions in the Pacific (e.g., Clarke, 2008, and references therein).

Given only the Argo data, one cannot unambiguously assess heat budgets for the various layers over the different basins. One possible interpretation is that net Pacific Ocean heat storage is owing to local surface heat exchanges with the atmosphere. This interpretation assumes no contributions from the deep ocean $(>2000 \mathrm{~m})$ and no fluxes between basins, and demands heat fluxes from the thermocline layer to the surface and intermediate layers (Fig. 4). Our interpretation is supported by Mayer et al. (2014), who argue that ocean heat storage over the tropical Pacific $\left(30^{\circ} \mathrm{S}-30^{\circ} \mathrm{N}\right)$ during ENSO is balanced by surface heat exchanges. Other interpretations are possible given the data, but would imply that surface heat fluxes over every other basin are balanced and compensated by ocean heat transports out of or into that basin. Any more definitive diagnosis of the heat budgets would require a more advanced approach. For example, future studies could use an ocean state estimate covering the altimetric era (e.g., Forget et al., 2015), not only to investi- 
(a) Global

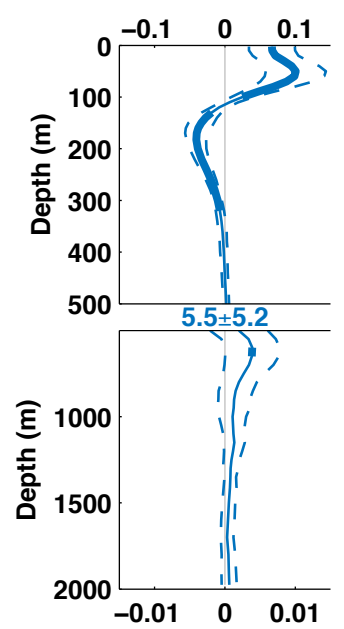

(b) Pacific

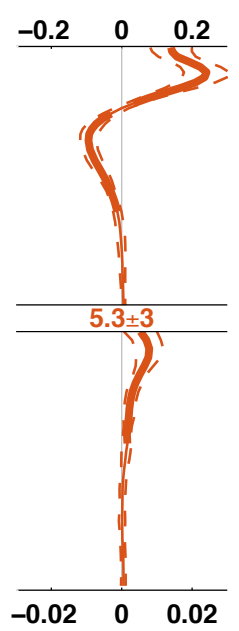

(c) Indian

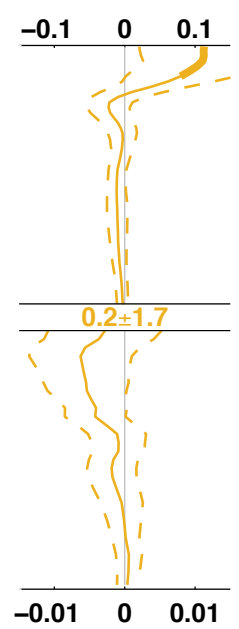

(d) Atlantic

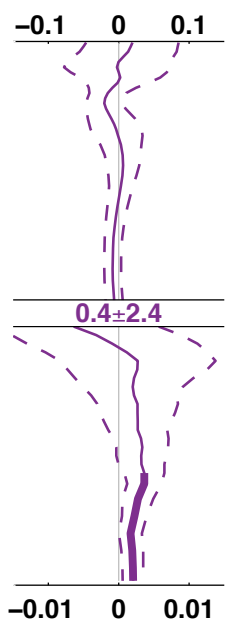

(e) Southern

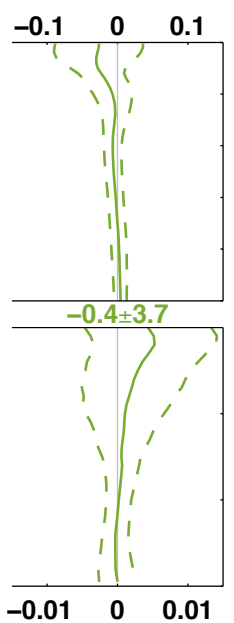

Figure 3. Coefficients of regressions of Argo potential temperature on the MEI $\left({ }^{\circ} \mathrm{C}\right.$ per MEI) over 2005-2015 over (a) the global ocean and the (b) Pacific, (c) Indian, (d) Atlantic, and (e) Southern (south of $30^{\circ} \mathrm{S}$ ) basins. Solid lines are the regression coefficients and dashed lines mark the $90 \%$ confidence interval. Bold lines mark significance at the $95 \%$ confidence level (i.e., one-tailed test). Note the different horizontal axis limits between the top and bottom panels. The colored values between the top and bottom panels represent the total ocean heat storage (units of ZJ per MEI; $1 \mathrm{ZJ} \equiv 10^{21} \mathrm{~J}$ ) integrated over $0-2000 \mathrm{~m}$ in the different basins given as $90 \%$ confidence intervals. For this figure, the Indian Ocean was defined as between 31.5 and $122.5^{\circ} \mathrm{E}$ and north of $30.5^{\circ} \mathrm{S}$, the Atlantic Ocean between $76.5^{\circ} \mathrm{W}$ and $14.5^{\circ} \mathrm{E}$ and north of $30.5^{\circ} \mathrm{S}$, the Pacific Ocean between $118.5^{\circ} \mathrm{E}$ and $69.5^{\circ} \mathrm{W}$ and north of $30.5^{\circ} \mathrm{S}$, and the Southern Ocean south of $30.5^{\circ} \mathrm{S}$.

gate a longer time period and corroborate or refute the purely observational results presented here, but also to better understand the physical processes contributing to the global and regional steric changes (cf. Piecuch and Ponte, 2011, 2014).

Previous studies suggest that both the global ocean and climate system lose heat during El Niño events (e.g., Roemmich and Gilson, 2011; Loeb et al., 2012; Trenberth et al., 2014). This would appear to conflict with our finding that the ocean is warmer during El Niños. However, the discrepancy is only apparent, since we consider ocean heat content and those past studies focus on the ocean heat content tendency (i.e., its rate of change). Moreover, scrutinizing visual examination of the earlier results (e.g., Fig. 8 in Trenberth et al., 2014) suggests that there is a phase lag between ENSO and the heat content tendency, such that warming precedes El Niño peaks and cooling follows peaks. This would be fully consistent with our findings, and those of von Schuckmann et al. (2014), who show a negative global ocean heat content anomaly during the 2010-2011 La Niña. Future studies should investigate in closer detail the coherence between variations in ocean heat content and ENSO.

The vertical structure of ocean temperature changes during ENSO events found here (Fig. 3) has implications for understanding which ocean regions and depth levels contributed to the recent "surface warming slowdown", which some partly relate to the dominant La Niña phase of the 2000s relative to the 1990s (Kosaka and Xie, 2013; Cazenave et al., 2014; England et al., 2014; Risbey et al, 2014). Nieves et al. (2015) determine that the slowdown was caused by a decadal shift

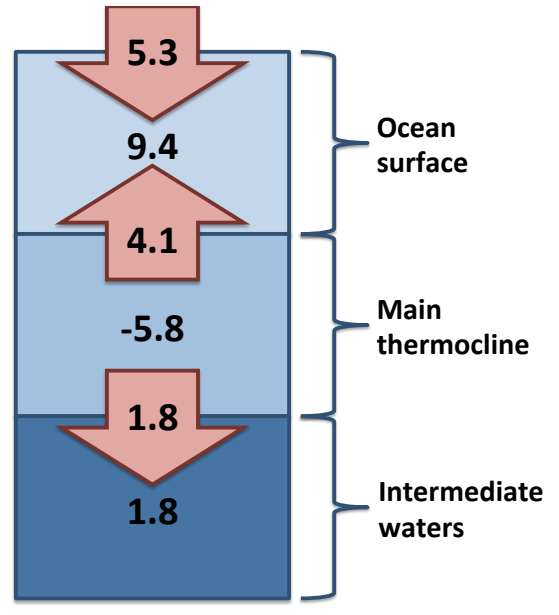

Figure 4. Hypothesized Pacific heat budget during El Niño events. The blue blocks are the ocean surface $(0-110 \mathrm{~m})$, main thermocline $(120-380 \mathrm{~m})$, and intermediate water $(400-2000 \mathrm{~m})$ layers. The red arrows are heat exchanges between the ocean layers or with the overlying atmosphere. Black values are either the total ocean heat storage within the layers as given by Argo data or the required heat exchanged between them under the stated assumptions of no transports between ocean basins and no contributions from the deep ( $>2000 \mathrm{~m}$ ) ocean. Units are ZJ per unit MEI. (Note that all arrows and signs, shown here for El Niño, would be reversed for La Niña.)

in Indo-Pacific heating; they show that the Pacific Ocean above $100 \mathrm{~m}$ cooled while the Indian Ocean between 100 and 


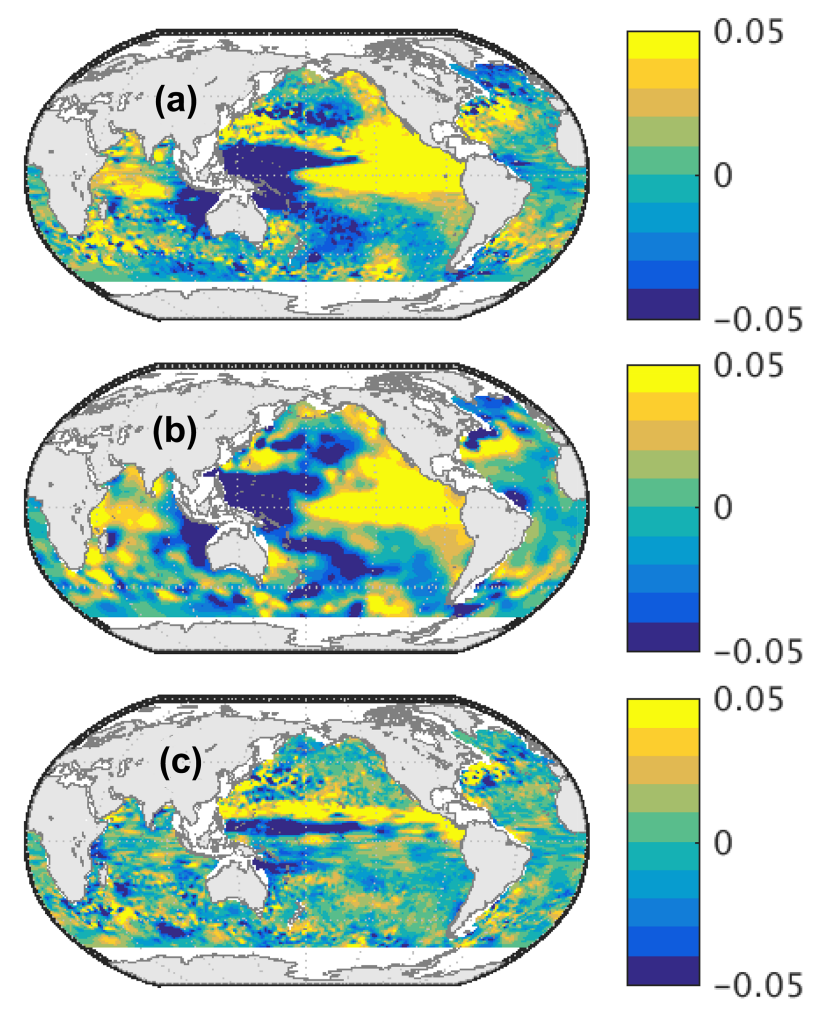

Figure 5. (a) Spatial pattern of nonseasonal anomalous Argo steric sea level (relative to 2005-2015 with linear trends and annual cycles removed) computed from the SIO gridded dataset over the last 6 months (July-December) of 2015. (b) As in (a) but computed from the IPRC gridded dataset. (c) Spatial pattern of the difference between the two gridded datasets (i.e., SIO minus IPRC). All panels have units of $\mathrm{cm}$ steric sea level.

$300 \mathrm{~m}$ warmed from the 1990 s to the 2000 s, but that the rate of global ocean heat storage above $1500 \mathrm{~m}$ did not change during that time. Our results (Fig. 3) suggest that cooling of the surface Pacific between the 2 decades is consistent with phasing of ENSO, but subsurface Indian warming and lack of net ocean warming or cooling are not, hinting that processes unrelated to ENSO also contributed to the surface warming slowdown, consonant with papers showing an important role for the Interdecadal Pacific Oscillation (Meehl et al., 2013; Trenberth and Fasullo, 2013; Steinman et al., 2015; Fyfe et al., 2016).

In this study, SIO and IPRC Argo datasets were considered. While reflected in the standard errors, differences between these two products are apparent. For example, while both curves evidence an overall increase from the beginning of 2011 to the middle of 2015, the SIO and IPRC global steric height series diverge thereafter, with IPRC turning down and decreasing, and SIO continuing to rise through the latter half of 2015 (Fig. 1d). These global differences stem from regional discrepancies (Fig. 5). Nonseasonal steric height patterns over the global ocean from SIO and IPRC from July to December 2015 are generally similar, but mani- fest clear discrepancies in the North Pacific, such that SIO shows more negative values than IPRC near the Equator towards the west, and more positive values over the tropics more broadly (Fig. 5c). Differences between the datasets could be due to different data sources, vertical resolution, or processing strategies, and more detailed future studies should more definitively attribute such discrepancies. Results shown in Llovel et al. (2014) attest to similar differences between SIO and IPRC datasets with regard to the global steric height trend over 2005-2013. Our qualitative conclusions are robust to such quantitative differences between the Argo datasets; for example, employing either SIO or IPRC only, the GMSL budget related to ENSO closes (not shown), and it is unlikely ( $<33 \%$ likelihood) that the barystatic term contributes $>68 \%$ to the sum of barystatic and thermosteric contributions to the GMSL changes linked to ENSO (Fig. 2).

Finally, nonseasonal anomalous GMSL was considerably higher during the 2014-2015 El Niño than during the 19971998 El Niño (Fig. 6), which is noteworthy because these two El Niño events were comparable in amplitude. (In addition to the distinct axis limits, Figs. 1a and 6 differ in that the removed linear trend and annual cycle are estimated for 20052015 in the former and 1993-2015 in the latter.) This could suggest that the relationship between GMSL and ENSO is a complicated function of time period and frequency band, in which case the results presented here apply strictly to the study period. However, it could also suggest that other climate modes (e.g., Pacific Decadal Oscillation, e.g., Hamlington et al., 2016) exert an influence on GMSL that has yet to be discussed.

\section{Conclusions}

It has long been known that nonseasonal variations in global-mean sea level (GMSL) are correlated with El NiñoSouthern Oscillation (ENSO), but the nature of such GMSL fluctuations tied to ENSO, whether steric or barystatic, has remained unclear. We used linear estimation to consider a decade's worth of altimetry, GRACE, and Argo data processed by different research centers, thus clarifying the nature of the GMSL balance related to ENSO. Fluctuations in ENSO, GMSL, and barystatic and steric terms are significantly correlated (Fig. 1). Barystatic and steric components render comparable contributions to GMSL changes during ENSO events (Table 1). The steric contributions reflect ocean heat storage across various depths in the Pacific Ocean (Fig. 3). We offered a heuristic interpretation of the Pacific heat budget during ENSO periods in terms of diabatic exchanges at the sea surface and adiabatic redistributions within the ocean interior (Fig. 4), but more work is needed in the future to diagnose more definitively the relative contributions of surface fluxes, interbasin exchanges, vertical transports, and the deep ocean to the heat budgets. More work is also needed to understand differences between grid- 


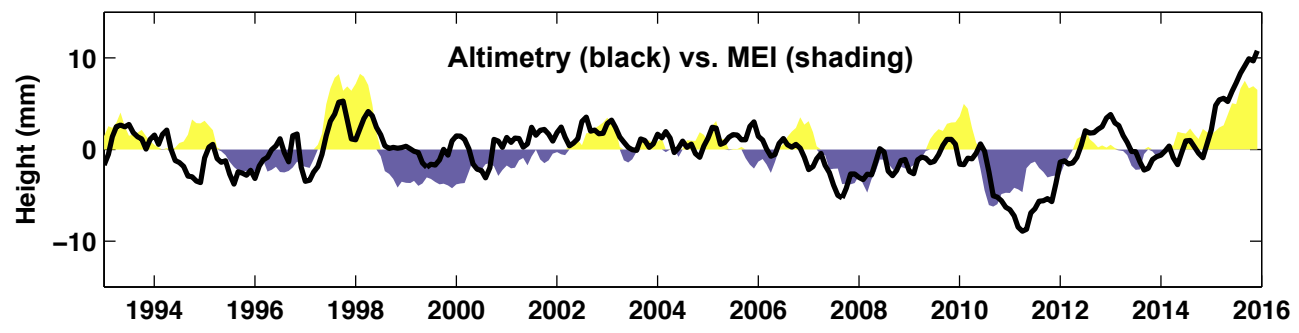

Figure 6. Nonseasonal anomalies of GMSL (black) and MEI (shading) over 1993-2015.

ded Argo datasets (Fig. 5) and to determine why the anomalous GMSL response to ENSO was apparently much stronger during the 2014-2015 El Niño than during the 1997-1998 El Niño (Fig. 6). Our results corroborate previous suggestions made based on models (Landerer et al., 2008) or observations during an isolated event (Dieng et al., 2014, 2015) that steric contributions to ENSO-related GMSL fluctuations are not negligible relative to barystatic contributions. These findings also have implications more generally for understanding the ocean's role in the planet's radiation imbalance and hydrological cycle.

\section{Data availability}

Data used in this study are available from the sources detailed in Appendix Table E1. Matlab code for processing these data and creating the figures here are available from the first author upon request. 


\section{Appendix A: Description of the OLS method}

Let us regard the altimetric GMSL record (or any other data series for that matter) $Y$ for 2005-2015 (including trend and annual cycle) as a linear combination of predictors $X$ :

$Y=X \beta+\varepsilon$.

Here $X$ includes the linear trend (slope and intercept), annual cycle (sine and cosine), and MEI, $\varepsilon$ is the error term, and $\beta$ contains the regression coefficients to be solved for. The OLS estimator for $\beta$ is that vector which minimizes the variance between $Y$ and $X \beta$,

$\hat{\beta}=M Y$,

where $M \doteq\left(X^{\mathbf{T}} X\right)^{-1} X^{\mathbf{T}}$ is the Moore-Penrose pseudoinverse and $\mathbf{T}$ is the matrix transpose. While OLS assumes white noise residuals, we find that $\varepsilon$ is autocorrelated (not shown). Thus, we assume a first-order autoregressive model, inflating the OLS standard errors by computing the lag-1 autocorrelation $\varphi$ and finding the effective number of data points $n^{*}$,

$n^{*}=n\left(\frac{1-\varphi}{1+\varphi}\right)$,

where here $n=132$ months of observations over 2005-2015. This effective number of data points is then used for determining the OLS standard error for the regression coefficients,

$\hat{\sigma}_{\hat{\beta}_{j}}=\sqrt{\frac{\varepsilon^{\mathbf{T}} \varepsilon}{n^{*}-k}\left(X^{\mathbf{T}} X\right)_{j j}^{-1}}$,

where $\hat{\beta}_{j}$ is the $j$ th coefficient and $k=5$ is the total number of coefficients being estimated. Similar methods are described by Chambers et al. (2012) and Calafat and Chambers (2013). Other methods are possible for linear estimation in the presence of autocorrelated residuals (e.g., feasible generalized least squares), but we find that - in this context these methods result in endogenous predictors (specifically, residuals of the fit are significantly correlated with the MEI predictor term), hence inconsistent estimates, and so are not employed.

\section{Appendix B: Evaluation of $90 \%$ confidence intervals}

All values derived from OLS regression quoted in the main text, shown in Fig. 3, and given in Table 1, are $90 \%$ confidence intervals. These intervals are determined as follows. First, to account for goodness of fit, we compute the OLS standard errors, adjusting values according to the effective degrees of freedom, as above. Second, to account for uncertainty in the data, we propagate the standard errors in the data based on the OLS estimator and the usual procedures for uncertainty propagation (e.g., Thomson and Emery, 2014),

$\delta_{\hat{\beta}_{j}}=\delta_{Y} \sqrt{\left(M M^{\mathbf{T}}\right)_{j j}}$,

where $\delta_{Y}$ represents the standard error on the altimetry, GRACE, or Argo data as outlined in the text and given in Table 1 . We use $\hat{\sigma}_{\hat{\beta}_{j}}$ and $\delta_{\hat{\beta}_{j}}$ to evaluate the total uncertainty $e_{\hat{\beta}_{j}}$,

$e_{\hat{\beta}_{j}}=\sqrt{\hat{\sigma}_{\hat{\beta}_{j}}^{2}+\delta_{\hat{\beta}_{j}}^{2}}$.

Using these values for the total errors, the $90 \%$ confidence intervals are constructed as

$\hat{\beta}_{j}-t_{95} \cdot e_{\hat{\beta}_{j}} \leq \beta_{j} \leq \hat{\beta}_{j}+t_{95} \cdot e_{\hat{\beta}_{j}}$,

where $\beta_{j}$ is the true value of the $j$ th coefficient and $t_{95}$ is the ninety-fifth percentile of the Student's $t$ inverse cumulative distribution given the effective degrees of freedom (Table 1).

\section{Appendix C: Budgets for the annual cycle and linear trend}

Here we briefly consider the GMSL budget for the annual cycle and the linear trend. These cases have been discussed before in many previous investigations (e.g., Leuliette, 2015, and references therein), and are discussed here mainly for the sake of completeness. Altimetry gives a GMSL trend over $2005-2015$ of $3.39 \pm 0.55 \mathrm{~mm} \mathrm{yr}^{-1}$, whereas the sum of GRACE and Argo yields $3.22 \pm 0.43 \mathrm{~mm} \mathrm{yr}^{-1}$ (Table 1). The residual between these two values $0.18 \pm 0.19 \mathrm{~mm} \mathrm{yr}^{-1}$ is not statistically distinguishable from zero at the $95 \%$ confidence level. We see that GRACE barystatic contributes roughly two-thirds to the total change $\left(2.23 \pm 0.44 \mathrm{~mm} \mathrm{yr}^{-1}\right)$, whereas Argo steric contributes about one-third $(0.99 \pm$ $0.16 \mathrm{~mm} \mathrm{yr}^{-1}$ ). The general closure of the budget and the relative partitioning between barystatic and steric effects is very similar to other studies for similar periods (e.g., see Leuliette, 2015, for an assessment of the observed GMSL budget for 2005-2013).

The amplitude of the GMSL annual cycle from altimetry is very similar to that from the sum of GRACE and Argo (Table 1). Also, we notice that the barystatic and steric annual cycles are roughly in antiphase, which leads to a GMSL annual cycle that is smaller in amplitude than the barystatic annual cycle. This feature has been noted and discussed in numerous previous studies (e.g., Leuliette and Miller, 2009). However, we note that, due to a slight phase difference between GMSL from altimetry and from GRACE and Argo (Table 1), there is actually a statistically significant residual in the annual cycle. While this is not made explicit in previous studies, it is implicit; for example, Leuliette and 
Miller (2009) show a similar difference in GMSL phase between altimetry and the sum of Argo and GRACE. It is not immediately obvious what is responsible for this discrepancy, and it is beyond our scope to explore the issue in depth. However, we hypothesize that it is due to sampling errors in the observing system, namely the fact that Argo does not sample at high latitudes or, probably more importantly, on shallow continental shelf seas.

\section{Appendix D: Description of Monte Carlo simulation}

We evaluate what the likelihood is that the barystatic sea level term contributes more to ENSO-related GMSL fluctuations than the steric sea level term. We make this evaluation probabilistically, performing 100000 iterations of drawing two values, each one drawn from a separate Student $t$ distribution. The first distribution is based on the MEI regression coefficient for the GRACE barystatic term, with location parameter equal to the regression coefficient, scale parameter equal to the standard error of the regression coefficient, and using the effective degrees of freedom. A draw from this first distribution is a possible value of the barystatic contribution. Likewise, the second distribution is based on the MEI regression coefficient for the Argo steric term, with draws from this second distribution being possible values for the steric contribution. For each iteration, we assess the fraction,

$F=D_{1} /\left(D_{1}+D_{2}\right)$,

where $D_{1}$ and $D_{2}$ are the draws from the first and second distributions, respectively. Physically, $F$ represents the fractional barystatic contribution to the total GMSL change. The histogram $P$ is derived from the realizations of $F$. Figure 2 displays the likelihood,

$L(x)=1-\int_{-\infty}^{x} P\left(x^{\prime}\right) \mathrm{d} x^{\prime}$,

where $L(x)$ is the probability (i.e., fraction of iterations) that $F>x$. For example, $L(0.6)$ is the likelihood that the barystatic term is responsible for $>60 \%$ of total GMSL change.

\section{Appendix E: Datasets}

\section{E1 Satellite altimetry}

The AVISO (Archiving, Validation, and Interpretation of Satellite Oceanographic data service) data were downloaded from the AVISO website (Table E1). The data are based on reference missions (Ocean Topography Experiment (TOPEX)/Poseidon and Jason series) with inverted barometer correction applied, the seasonal signal retained, and glacial isostatic adjustment applied.

The CSIRO (Commonwealth Scientific and Industrial Research Organisation) data were downloaded from the CSIRO website (Table E1). The version of the data used here had the inverse barometer and glacial isostatic adjustment corrections applied and the seasonal signals not removed (“jb_iby_srn_gtn_giy"). A 60-day smoothing was used to reduce a spurious 59-day cycle in the data related to alias of the ocean tides.

The Colorado data were downloaded from the Colorado sea level website (Table E1). The data version is version_2016rel2. A 60-day boxcar filter was also applied to the data.

The NOAA (National Oceanic and Atmospheric Administration) data were downloaded from the NOAA website (Table E1). The product used here is based on TOPEX/Poseidon and Jason series data with the seasonal signals retained. A 60-day smoothing was applied to these data and a trend of $0.3 \mathrm{~mm} \mathrm{yr}^{-1}$ was added to account for glacial isostatic adjustment effects not accounted for in this product.

\section{E2 Profiling floats}

The SIO Argo data were downloaded from the SIO website (Table E1). We used the 2004-2014 climatologies with the provided monthly extensions through February 2016.

The IPRC gridded data fields were downloaded from the IPRC website (see Table E1).

\section{E3 Gravimetric retrievals}

The GRACE data were downloaded from Don P. Chambers' Dropbox folder (Table E1). Data gaps and missing months in these time series were filled based on cubic interpolation.

\section{E4 Climate indices}

MEI values were downloaded from the NOAA ENSO website (Table E1). 
Table E1. Locations and sources of the data used here. Websites accessible as of 2 June 2016.

\begin{tabular}{lll}
\hline Dataset & Source & Location \\
\hline Altimetry & AVISO & http://www.aviso.altimetry.fr/en/data/products/ocean-indicators-products/ \\
Altimetry & Colorado & http://sealevel.colorado.edu/ \\
Altimetry & NOAA & http://www.star.nesdis.noaa.gov/sod/lsa/SeaLevelRise/ \\
Altimetry & CSIRO & http://www.cmar.csiro.au/sealevel/sl_data_cmar.html \\
Argo & SIO & http://sio-argo.ucsd.edu/RG_Climatology.html \\
Argo & IPRC & http://apdrc.soest.hawaii.edu/las/v6/dataset?catitem=3 \\
GRACE & CSR & https://dl.dropboxusercontent.com/u/31563267/ocean_mass_orig.txt \\
GRACE & JPL & https://dl.dropboxusercontent.com/u/31563267/ocean_mass_orig.txt \\
GRACE & GFZ & https://dl.dropboxusercontent.com/u/31563267/ocean_mass_orig.txt \\
MEI & NOAA & http://www.esrl.noaa.gov/psd/enso/ \\
\hline
\end{tabular}


Acknowledgements. Support for this research came from NASA grants NNX14AJ51G and NNH16CT00C. Helpful conversations with Steve Nerem, Rui Ponte, Don Chambers, and John Gilson are acknowledged. Two anonymous reviewers made valuable comments and suggestions, especially with respect to comparing the Argo datasets. The providers of the datasets are formally acknowledged in Appendix E and Table E1.

Edited by: M. Hoppema

Reviewed by: two anonymous referees

\section{References}

Ablain, M., Cazenave, A., Valladeau, G., and Guinehut, S.: A new assessment of the error budget of global mean sea level rate estimated by satellite altimetry over 1993-2008, Ocean Sci., 5, 193201, doi:10.5194/os-5-193-2009, 2009.

Bettadpur, S.: CSR Level-2 Processing Standards Document for Product Release 05 GRACE 327-742, revision 4.0, 2012

Boening, C., Willis, J. K.., Landerer, F. W., Nerem, R. S., and Fasullo, J.: The 2011 La Niña: So strong, the oceans fell, Geophys. Res. Lett., 39, L19602, doi:10.1029/2012GL053055, 2012.

Calafat, F. M. and Chambers, D. P.: Quantifying recent acceleration in sea level unrelated to internal climate variability, Geophys. Res. Lett., 40, 3661-3666, 2013

Calafat, F. M., Chambers, D. P., and Tsimplis, M. N.: On the ability of global sea level reconstructions to determine trends and variability, J. Geophys. Res.-Oceans, 119, 1572-1592, doi:10.1002/2013JC009298, 2014.

Cazenave, A., Dominh, K., Guinehut, S., Berthier, E., Llovel, W., Ramillien, G., Ablain, M., and Lamicol, G.: Sea level budget over 2003-2008: A reevaluation from GRACE space gravimetry, satellite altimetry and Argo, Global Planet. Change, 65, 83-88, 2009.

Cazenave, A., Henry, O., Munier, S., Delcroix, T., Gordon, A. L., Meyssignac, B., Llovel, W., Palanisamy, H., and Becker, M.: Estimating ENSO Influence on the Global Mean Sea Level, 19932010, Mar. Geod., 35, 82-97, 2012.

Cazenave, A., Dieng, H.-B., Meyssignac, B., von Schuckmann, K., Decharme, B., and Berthier, E.: The rate of sea-level rise, Nature Climate Change, 4, 358-361, 2014.

Chambers, D. P. and Bonin, J. A.: Evaluation of Release-05 GRACE time-variable gravity coefficients over the ocean, Ocean Sci., 8, 859-868, doi:10.5194/os-8-859-2012, 2012.

Chambers, D. P., Mehlhaff, C. A., Urban, T. J., Fujii, D., and Nerem, R. S.: Low-frequency variations in global mean sea level: 1950-2000, J. Geophys. Res., 107, C43026, doi:10.1029/2001JC001089, 2002.

Chambers, D. P., Merrifield, M. A., and Nerem, R. S.: Is there a 60year oscillation in global mean sea level?, Geophys. Res. Lett., 39, L18607, doi:10.1029/2012GL052885, 2012.

Church, J. A. and White, N. J.: Sea-Level Rise from the Late 19th to the Early 21st Century, Surv. Geophys., 32, 585-602, 2011.

Clarke, A. J.: An Introduction to the Dynamics of El Nino \& the Southern Oscillation, Academic Press, 324 pp., 2008.

de Linage, C., Kim, H., Famiglietti, J. S., and Yu, J.-Y.: Impact of Pacific and Atlantic sea surface temperatures on interannual and decadal variations of GRACE land water storage in tropi- cal South America, J. Geophys. Res. Atmos., 118, 10811-10829, 2013.

Dahle, C.: GFZ Level-2 Processing Standards Document for Product Release 05 GRACE 327-742, revision 1.1, 2013.

Dieng, H. B., Cazenave, A., Meyssignac, B., Henry, O., von Schuckmann, K., Palanisamy, H., and Lemoine, J. M.: Effect of La Niña on the global mean sea level and north Pacific ocean mass over 2005-2011, J. Geod. Sci., 4, 19-27, 2014.

Dieng, H. B., Palanisamy, H., Cazenave, A., Meyssignac, B., and von Schuckmann, K.: The Sea Level Budget Since 2003: Inference on the Deep Ocean Heat Content, Surv. Geophys., 36, 2, 209-229, doi:10.1007/s10712-015-9314-6, 2015.

Eicker, A., Forootan, E., Springer, A., Longuevergne, L., and Kusche, J.: Does GRACE see the terrestrial water cycle "intensifying”?, J. Geophys. Res. Atmos., 121, 733-745, 2016.

England, M. H., McGregor, S., Spence, P., Meehl, G. A., Timmermann, A., Cai, W., Sen Gupta, A., McPhaden, M. J., Purich, A., and Santoso, A.: Recent intensification of wind-driven circulation in the Pacific and the ongoing warming hiatus, Nature Climate Change, 4, 222-227, 2014.

Fasullo, J. T., Boening, C., Landerer, F. W., and Nerem, R. S.: Australia's unique influence on global sea level in 2010-2011, Geophys. Res. Lett., 40, 4368-4373, 2013.

Forget, G., Campin, J.-M., Heimbach, P., Hill, C. N., Ponte, R. M., and Wunsch, C.: ECCO version 4: an integrated framework for non-linear inverse modeling and global ocean state estimation, Geosci. Model Dev., 8, 3071-3104, doi:10.5194/gmd-8-30712015, 2015.

Fyfe, J. C., Meehl, G. A., England, M. H., Mann, M. E., Santer, B. D., Flato, G. M., Hawkins, E., Gillett, N. P., Xie, S.-P., Kosaka, Y., and Swart, N. C.: Making sense of the early-2000s warming slowdown, Nature Climate Change, 6, 224-228, 2016.

Gill, A. E. and Niiler, P. P.: The theory of the seasonal variability in the ocean, Deep-Sea Res., 20, 141-177, 1973.

Gregory, J. M., White, N. J., Church, J. A., Bierkens, M. F. P., Box, J. E., van den Broeke, M. R., Cogley, J. G., Fettweis, X., Hanna, E., Huybrechts, P., Konikow, L. F., Leclercq, P. W., Marzeion, B., Oerlemans, J., Tamisiea, M. E., Wada, Y., Wake, L. M., and van de Wal, R. S. W.: Twentieth-Century Global-Mean Sea Level Rise: Is the Whole Greater than the Sum of the Parts? J. Clim., 26, 4476-4499, 2013.

Haddad, M., Taibi, H., and Areski, S. M. M.: On the recent global mean sea level changes: Trend extraction and El Niño's impact, C. R. Geosci., 345, 167-175, 2013.

Hamlington, B. D., Cheon, S. H., Thompson, P. R., Merrifield, M. A., Nerem, R. S., Leben, R. R., and Kim, K.-Y.: An ongoing shift in Pacific Ocean sea level, J. Geophys. Res.-Oceans, 121, 50845097, doi:10.1002/2016JC011815, 2016.

Johnson, G. C. and Chambers, D. P.: Ocean bottom pressure seasonal cycles and decadal trends from GRACE Release-05: Ocean circulation implications, J. Geophys. Res.-Oceans, 118, 42284240, 2013.

Kosaka, Y. and Xie, S.-P.: Recent global-warming hiatus tied to equatorial Pacific surface cooling, Nature, 501, 403-407, 2013.

Landerer, F. W., Jungclaus, J. H., and Marotzke, J.: El NiñoSouthern Oscillation signals in sea level, surface mass redistribution, and degree-two geoid coefficients, J. Geophys. Res., 113, C08014, doi:10.1029/2008JC004767, 2008. 
Leuliette, E.: The Budget of Recent Global Sea Level Rise 20052013, NOAA NESDID Report, 10 pp., 2014.

Leuliette, E. W.: The Balancing of the Sea-Level Budget, Curr. Clim. Change Rep., 1, 185-191, 2015.

Leuliette, E. W. and Miller, L.: Closing the sea level rise budget with altimetry, Argo, and GRACE, Geophys. Res. Lett., 36, L04608, doi:10.1029/2008GL036010, 2009.

Leuliette, E. W. and Scharroo, R.: Integrating Jason-2 into a multiple-altimeter climate data record, Mar. Geod., 33, 504, doi:10.1080/01490419.2010.487795, 2010.

Leuliette, E. W. and Willis, J. K.: Balancing the sea level budget, Oceanography, 24, 2, 122-129, 2011.

Llovel, W., Becker, M., Cazenave, A., Crétaux, J.-F., and Ramillien, G.: Global land water storage change from GRACE over 20022009; Inference on sea level, C. R. Geosci., 342, 179-188, 2010.

Llovel, W., Becker, M., Cazenave, A., Jevrejeva, S., Alkama, R., Decharme, B., Douville, H., Ablain, M., and Beckley, B.: Terrestrial waters and sea level variations on interannual time scale, Global Planet. Change, 75, 76-82, 2011.

Llovel, W., Willis, J. K., Landerer, F. W., and Fukumori, I.: Deepocean contribution to sea level and energy budget not detectable over the past decade, Nature Climate Change, 4, 1031-1035, 2014.

Loeb, N. G., Lyman, J. M., Johnson, G. C., Allan, R. P., Doelling, D. R., Wong, T., Soden, B. J., and Stephens, G. L.: Observed changes in top-of-the-atmosphere radiation and upper-ocean heating consistent within uncertainty, Nat. Geosci., 5, 110-113, 2012.

Lombard, A., Garcia, D., Ramillien, G., Cazenave, A., Biancale, R., Lemoine, J. M., Flechtner, F., Schmidt, R., and Ishii, M.: Estimation of steric sea level variations from combined GRACE and Jason-1 data, Earth Planet Sc. Lett., 254, 194-202, 2007.

Masters, D., Nerem, R. S., Choe, C., Leuliette, E., Beckley, B., White, N., and Ablain, M.: Comparison of Global Mean Sea Level Time Series from TOPEX/Poseidon, Jason-1, and Jason2, Mar. Geod., 35, 20-41, 2012.

Mayer, M., Haimberger, L., and Balmaseda, M. A.: On the Energy Exchange between Tropical Ocean Basins Related to ENSO, J. Clim., 27, 6393-6403, 2014.

Meehl, G. A., Hu, A., Arblaster, J. M., Fasullo, J., and Trenberth, K. E.: Externally Forced and Internally Generated Decadal Climate Variability Associated with the Interdecadal Pacific Oscillation, J. Clim., 26, 7298-7310, 2013.

Merrifield, M. A., Nerem, R. S., Mitchum, G. T., Miller, L., Leuliette, E., Gill, S., and Woodworth, P. L.: Sea level variations, 2008 annual assessment, in: State of the Climate in 2008, edited by: Peterson, T. C. and Baringer, M. O., 2009.

Meyssignac, B. and Cazenave, A.: Sea level: A review of presentday and recent-past changes and variability, J. Geodynam., 58, 96-109, 2012.

Meyssignac, B., Lemoine, J. M., Cheng, M., Cazenave, A., Gégout, P., and Maisongrande, P.: Interannual variations in degree-2 Earth's gravity coefficients $\mathrm{C} 2,0, \mathrm{C} 2,2$, and $\mathrm{S} 2,2$ reveal largescale mass transfers of climatic origin, Geophys. Res. Lett., 40, 4060-4065, 2013.

Munk, W.: Ocean Freshening, Sea Level Rising, Science, 300, 2041-2043. 2003.

Nerem, R. S., Chambers, D. P., Leuliette, E. W., Mitchum, G. T., and Giese, B. S.: Variations in global mean sea level associated with the 1997-1998 ENSO event: Implications for measuring long term sea level change, Geophys. Res. Lett., 26, 19, 30053008, 1999.

Nerem, R. S., Chambers, D. P., Choe, C., and Mitchum, G. T.: Estimating Mean Sea Level Change from the TOPEX and Jason Altimeter Missions, Mar. Geod., 33, 435-446, 2010.

Ngo-Duc, T., Laval, K., Polcher, J., and Cazenave, A.: Contribution of continental water to sea level variations during the 19971998 El Niño-Southern Oscillation event: Comparison between Atmospheric Model Intercomparison Project simulations and TOPEX/Poseidon satellite data, J. Geophys. Res., 110, D09103, doi:10.29/2004JD004940, 2005.

Nieves, V., Willis, J. K., and Patzert, W. C.: Recent hiatus caused by decadal shift in Indo-Pacific heating, Science, 349, 532-536, 2015.

Phillips, T., Nerem, R., Fox-Kemper, B., Famiglietti, J., and Rajagopalan, B.: The influence of ENSO on global terrestrial water storage using GRACE, Geophys. Res. Lett., 39, L16705, doi:10.1029/2012GL052495, 2012.

Piecuch, C. G. and Ponte, R. M.: Mechanisms of interannual steric sea level variability, Geophys. Res. Lett., 38, L15605, doi:10.1029/2011GL048440, 2011.

Piecuch, C. G. and Ponte, R. M.: Mechanisms of Global-Mean Steric Sea Level Change, J. Clim., 27, 824-834, 2014.

Ponte, R. M. and Dorandeu, J.: Uncertainties in ECMWF Surface Pressure Fields over the Ocean in Relation to Sea Level Analyses and Modeling, J. Atmos. Ocean. Tech., 20, 301-307, 2003.

Pugh, D. and Woodworth, P.: Sea-Level Science: Understanding Tides, Surges, Tsunamis and Mean Sea-Level Changes, Cambridge University Press, 395 pp., 2014.

Risbey, J. S., Lewandowsky, S., Langlais, C., Monselesan, D. P., O'Kane, T. J., and Oreskes, N.: Well-estimated global surface warming in climate projections selected for ENSO phase, Nature Climate Change, 4, 835-840, 2014.

Roemmich, D. and Gilson, J.: The 2004-2008 mean and annual cycle of temperature, salinity, and steric height in the global ocean from the Argo program, Prog. Oceanogr., 82, 81-100, 2009.

Roemmich, D. and Gilson, J.: The global ocean imprint of ENSO, Geophys. Res. Lett., 38, L13606, doi:10.1029/2011GL047992, 2011.

Stammer, D., Cazenave, A., Ponte, R. M., and Tamisiea, M. E.: Causes for Contemporary Regional Sea Level Changes, Annu. Rev. Mar. Sci., 5, 21-46, 2013.

Steinman, B. A., Mann, M. E., and Miller, S. K.: Atlantic and Pacific multidecadal oscillations and Northern Hemisphere temperatures, Science, 347, 988-992, 2015.

Tapley, B. D., Bettadpur, S., Watkins, M. and Reigber, C.: The gravity recovery and climate experiment: Mission overview and early results, Geophys. Res. Lett., 31, L09607, doi:10.1029/2004GL019920, 2004.

Thomson, R. E. and Emery, W. J.: Data Analysis Methods in Physical Oceanography, Third Edition, Elsevier, 716 pp., 2014.

Trenberth, K. E. and Fasullo, J. T.: An apparent hiatus in global warming?, Earth's Future, 1, 19-32, 2013.

Trenberth, K. E., Fasullo, J. T., and Balmaseda, M. A.: Earth's Energy Imbalance, J. Clim., 27, 3129-3144, 2014.

von Schuckmann, K., Sallée, J.-B., Chambers, D., Le Traon, P.Y., Cabanes, C., Faillard, F., Speich, S., and Hamon, M.: Consistency of the current global ocean observing system from an 
Argo perspective, Ocean Sci., 10, 547-557, doi:10.5194/os-10547-2014, 2014.

Watkins, M. and Yuan, D.: JPL Level-2 Processing Standards Document for Product Release 05 GRACE 327-742, revision 5.0, 2012.
Willis, J. K., Chambers, D. P., and Nerem, R. S.: Assessing the globally averaged sea level budget on seasonal to interannual timscales, J. Geophys. Res., 113, C06015, doi:10.1029/2007JC004517, 2008.

Wolter, K. and Timlin, M. S.: Measuring the strength of ENSO events: How does 1997/98 rank?, Weather, 53, 315-324, 1998. 